\title{
Teacher resistance to educational change in the United Arab
} Emirates

Ibrahim, Ali S. $\triangle$

College of Education, United Arab Emirates University, UAE (ibrahim6@gmail.com; alisaidebrahim@uaeu.ac.ae)

Al-Kaabi, Ali

College of Education, United Arab Emirates University,UAE (ali.alkaabi@uaeu.ac.ae)

El-Zaatari, Wafaa

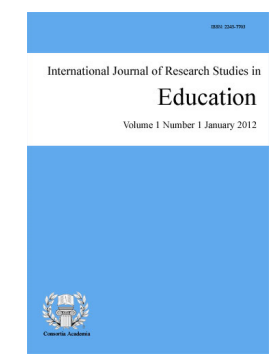

ISSN: $2243-7703$ Online ISSN: 2243-7711

College of Education, United Arab Emirates University, UAE (wafaaz71@ gmail.com)

OPEN ACCESS

\section{Abstract}

This study investigated four factors for teacher resistance to educational change in government schools in the UAE: psychological, personal, school-culture-related, and organizational. Data were collected through a survey of 39 statements on a Likert scale completed by 255 male and female, foreign and national teachers who taught different grade levels in Al-Ain government schools. The findings of the study showed that teachers felt the need for change and trusted change agents and principals. However, they needed to be prepared psychologically because they were afraid of the unknown consequences of change. They were also exhausted by frequent changes that they felt were imposed. Further, they faced difficulties in teaching students who were not grasping the new curriculum because of the English language barrier. The study recommended that well-planned changes, supportive principals, change-based effective professional development, and a reward system are needed for the change to succeed. Above all, change should fit the UAE culture.

Keywords: resistance to change; teachers; education reform; United Arab Emirates 


\section{Teacher resistance to educational change in the United Arab Emirates}

\section{Introduction}

In recent decades, education has undergone constant change under the effects of globalization, advances in information and communication technology, and the work of multinational and bilateral organizations in education. Education witnesses a movement toward certain patterns of teaching and learning, administration, assessment, and school-society relations. These patterns push for teaching and learning techniques that are more student-centered, administration that is shared and collaborative, assessment that is continuous and formative, and connection between school and home that is based on partnership.

To respond to those changes, the United Arab Emirates (UAE) attempts to position itself as a country that adopts the most recent waves of reform. Therefore, educational institutions in the UAE are undergoing tremendous changes. The current wave of change-which can be seen in light of the decentralization rhetoric — started in 2005 when the Ministry of Education delegated the responsibility of education in the emirate of Abu Dhabi to the Abu Dhabi Education Council (ADEC). Presently, ADEC supervises schools in the three school districts/zones/offices in the emirate. It has replaced the Ministry in all matters of education. The Ministry still bears the responsibility in Dubai and other Northern emirates.

Since its establishment, ADEC has exerted noticeable effort to infuse its agenda of change which is in line with major global changes in education as mentioned above. However, its effort for change faces many obstacles that arise from students, parents, teachers, and administrators. One of the most important obstacles is teachers' resistance to new changes. This resistance stems largely from how change is initiated and administered. Typically, change starts with ADEC planning for a certain change and then school principals are responsible for subsequent implementation. The expectation is that teachers will comply with the policies and plans. However, teachers sometimes struggle with the implementation of such pre-determined plans created by ADEC's officials.

In fact, resistance to change in the UAE has been documented by other researchers. In a study about curriculum change, Troudi and Alwan (2010) found that teachers had opposing reactions to curriculum change. They accepted the parts of change that they were more acquainted with but were distressed by other parts that required them to exert extra effort. One main reason for resisting change was the fact that teachers have been excluded from the decision making process. They felt low self-esteem since they viewed their work in the curriculum change as insignificant, inactive, and inferior. Teachers thought that their ideas were not considered because of the dominating and centralized nature of curriculum change.

In a study on change in teaching methodologies, Al-Ateeqi (2009) reached a similar conclusion. He indicated that not all teachers accept using "interactive teaching methodologies that promote creativity and innovation in teaching. Some [teachers] believe in traditional methods and old-fashioned teaching styles. This creates conflicts among educational administrators and policy makers on ... how ... children should be taught" (p. 88). Needless to say that such resistance to changes in the curriculum and teaching methodologies, in addition to other areas, will hinder the progress of the reform undertaken by ADEC.

It is worth mentioning that changes in curriculum and in teaching methods were in line with global changes that make students at the center of learning and they should be worthwhile and accepted by all stakeholders. However, in both studies teachers resisted the change. Therefore, the problem does not seem to be with the change but with some factors that might affect teachers to resist change. These factors are the focus of this study.

\subsection{Purpose and research questions}

As highlighted above, one of the major obstacles in improving the educational system in the UAE is teacher 
resistance. Therefore, the purpose of this study was to examine the factors for teacher resistance to educational change in Al-Ain government schools. More specifically, the study aimed to investigate the following research question: What are the underlying (psychological, personal, school-culture-related, organizational) factors for teacher resistance to educational change currently underway in Al-Ain government schools in the UAE?

This study was conducted in Al-Ain government schools only, and thus the findings of the study can not necessarily be generalized to all emirates in the UAE. The results of this study were also limited to the categories or factors of resistance that are mentioned in the research question.

\subsection{Significance of the study}

Resistance to educational change among teachers is a significant problem that exists globally. It is one of the challenges to successful implementation of change. Investigating the underlying factors behind resistance in the UAE will add to the body of international literature and investigating them in the UAE provides a unique and different example. The UAE is one of the conservative countries that employs foreign experts to help in planning for change and also employs foreign and expatriate teachers to help in carrying out the change. Therefore, the existence of many players in the education system in the UAE is significant.

Further, at a time of rapid educational changes that are currently occurring in the UAE government schools, scarce research has been done to find out how the change proceeds. The progress of change in those schools, we assume, is affected to a certain degree by the prevailing resistant attitudes among teachers. This study will explore those factors in Al-Ain government schools and help clarify the picture. This may provide policy makers and change agents with evidence about the factors for resistance that they may encounter. Moreover, the study can assist policy makers in developing the best ways to manage resistance in a constructive way and to move change forward. In addition, this study could be of help for teachers. When the psychological and personal resisting factors are identified, teachers may develop a sense of self-awareness. This might help them in changing their perceptions about change and make them more receptive of change that is based on international trends.

\section{Literature Review}

Change is defined as the creation of something unusual in various particular ways. It entails anything that is different from the norm (Flamholtz \& Randle, 2008). Educational change is the development of teachers', students', and administrators' knowledge, skills and dispositions in a way that is different from the present situation in order to stay functioning and competitive in such an ever changing society. Resistance to change occurs when people lack the interest in change, refrain from collaboration, and try to preserve the status quo. Palmer, Dunford, and Akin (2009) found that people do not always resist change. In fact, there are many reasons that encourage or discourage people to adopt change, such as security, money, authority, status, responsibility, working conditions, self-satisfaction, and time and effort needed.

In an attempt to develop this study's data collection instrument, literature was extensively reviewed to identify various factors for resisting change. These factors are classified into four categories: psychological, personal, school-culture-related, and organizational factors. The following sub-sections explore those factors in some details.

\subsection{Psychological factor}

Psychological factors have tremendous effect on teachers' resistance to change. Examples of these factors are the feelings of loss, threat, doubt, discomfort, and worries. Flamholtz and Randle (2008) found that change moves people away from what is known and comfortable to what is unusual and uncomfortable. This uneasiness leads people to resist change. Fullan and Ballew (2004) explained that people emotionally react when change is taking place. The "nature of change includes fear of loss and obsolescence and feeling of awkwardness. People 
often express doubts about new directions and sometimes outright opposition to them" (p. 97; see also Palmer et al., 2009).

Other psychological factors were highlighted by Van Veen and Sleegers (2006) who indicated that "the manner in which teachers react to educational reforms is largely determined by whether the teachers perceive their professional identities as being reinforced or threatened by reforms" (p. 109). Furthermore, resistance occurs when conflict arises due to the fact that the reality of teachers' background is not considered or when change is not given sufficient time to be incorporated into their philosophies (Flamholtz \& Randal, 2008). Besides, Margolis and Nagal (2006) asserted that cumulative stress from physical and mental exhaustion negatively affects the job performance and satisfaction. This stress will increase in relation to the extent and rate of change and the degree to which teachers perceive change to be imposed rather than shared. Considering these factors may help in achieving the psychological equanimity of teachers which, in turn, facilitates the successful implementation of change.

\subsection{Personal factor}

The personal factors are those factors that are associated with teachers' identities, attitudes, beliefs, adaptability, and trust. Van Veen and Sleegers (2006) explained that teachers will accept change only if it is in agreement with their specialty and skills. Gray (2002) pointed out that lack of trust, cultural- or age-related conservatism, different perceptions of external dangers or disagreement over the proposed strategy or change contribute to resistance of teachers.

Mckenzie and Scheurich (2008) added more personal factors that make teachers resist change. First, teachers blame external factors such as the carelessness of children, parents, neighborhood, culture and second language. Second, teachers perceive the accountability system as restrictive because they are always being watched and judged. Third, teachers consider any suggestion for change as criticism since they regard leaders as powerful and authoritarian. Finally, teachers resist change when it requires them to become more responsible because they do not want to position themselves in a higher position to other teachers. The conclusion is that if teachers see that change matches their attitudes and beliefs and is less threatening to them, they will be less likely to resist it.

\subsection{School-culture-related factor}

School culture has a great effect on the teachers' perception of change and its adoption or rejection. Per (2004) explained that cultural factors include how norms and values are shaped, how the work is organized, how interpersonal relations are created, and how the idea for change and renewal is interpreted in schools. In order for change to occur successfully, the norms and values represented by change should be in agreement with the organization's culture and its basic values. Otherwise, it will be resisted or rejected.

Examples of the cultural factors which help institutionalize change are the principals' positive styles of collaboration, communication, problem solving, and decision making. Kezar and Eckel (2002), for example, pointed out that institutional culture has a relationship to change in such a way that collaborative leadership appeared to affect change through a collegial cultural approach where motivation for change was observed. Besides, Palmer et al. (2009) indicated that change can be facilitated by having a common vision and effective communication strategies that help reinforce change.

The principals' behaviours are important in shaping the school culture and consequently facilitating or hindering change. Silcox, MacNeill, and Cavanagh (2003) explained that changing school culture necessitates having an efficient leader whose behaviors originate from moral values and beliefs that are congruent with change. The leader needs to share information and ideas about education with all stakeholders involved in the change process; raise their awareness about change; keep them informed; address their concerns; and assist in reducing their feelings of anxiety and frustration. DuFour, DuFour, and Eaker (2008, p. 156) added that change 
will be facilitated by having a principal who models the new behaviors and provides support for its application whenever needed. The principal needs also to trust teachers in carrying out change (Beckum, 2010; McGregor, 2002). Gaylor (2001) concluded that the more participation, trust, and communication are evident, the more teachers become open to change.

\subsection{Organizational factor}

In a time of change, what an organization needs is an effective leader who supports staff members and helps in organizing and planning for change; otherwise, resistance will prevail. Palmer et al. (2009) indicated that some teachers resist change because the proposed changes are inappropriate to the organization or that the timing of its introduction might not be suitable. Further, teachers resist change if they have gone through frequent changes in a limited period of time or if they have witnessed negative effects from previous changes.

Keeping teachers aware of change and training them on different components are important components of the organizational factor. In fact, when teachers are not provided professional development on change, they can easily resist it. Further, teachers should be involved in planning professional development activities. Kise (2005) and Silcox, MacNeill, and Cavanagh (2004) emphasized the significance of teachers' input in staff development programs and school reform efforts. However, Calabrese (2006) found that teachers seldom benefit from the training activities because of the limited time available for practice and the large amount of information they have to grasp. Therefore, the way professional development activities are planned and implemented affects the way teachers react to change.

Providing support and increasing teachers' motivation are also other organizational factors that the principal should consider while implementing change. Rayan and Ackerman (2005) stressed the importance of motivating teachers to follow a plan for change and supporting them to put it into action.

\section{Research Method}

This study used the quantitative approach, specifically the descriptive research method. The data were collected using a researchers-developed, self-administered survey that aimed to quantitatively assess the factors for resisting change.

\subsection{The population}

The population of this study was teachers in Al-Ain government schools in the UAE. The total number of teachers in Al-Ain school district was 4771 including 1948 male and 2823 female teachers. 2606 teachers were expatriates and 2165 teachers were national citizens (ADEC, 2010). They belonged to different age groups, levels of experience, and taught different grade levels.

\subsection{Sampling and participants}

The researchers applied stratified sampling. Strata were initially selected based on the type of schools. 18 schools were selected randomly and included nine male and nine female schools. The male and female schools were selected as three high, three preparatory, and three elementary schools. The researchers sent 23 surveys to each school totaling 414. The surveys were given to 207 male and 207 female teachers randomly chosen by the principal from the nine different grade levels. 255 teachers (102 males and 153 females) responded to the survey, which corresponds to a response rate of $62 \%$.

\subsection{The Instrument}

The researchers used a survey to explore the teacher attitudes toward change as well as the factors that affect teachers' resistance to change. Several steps were followed to develop this instrument. First, after an extensive 
literature review, lists of the most common factors that can enhance or hinder change were selected. Then, such factors were organized into four categories: psychological, personal, school-culture-related, and organizational. A total of 39 statements of closed-ended statements targeting these four factors were developed. Responses were noted on a 5-points Likert scale ranging from strongly disagree (1) to strongly agree (5). In addition, an open ended question was included at the end of each category for the respondents to write other three resisting factors they think were missing from each category.

\subsection{Validity and Reliability}

The content validity of the survey was established by using a jury of five specialists in the field of educational leadership. This jury judged the relevance of the instrument to the study, the belonging of each item to its subscale, and the wording of items. Some modifications were made based on their suggestions. Then, the instrument was pilot tested by asking ten randomly selected teachers from one of the government schools to complete the instrument. Some modifications were made based on teachers' feedback. Finally, after data collection, the instrument was checked for reliability by using Cronbach's alpha, which was 0.9 -indicating high reliability.

\subsection{Procedures}

After gaining approval from the superintendent of the Al-Ain School District, school principals distributed the questionnaire to teachers who were randomly selected from each school. All participants were informed before the commencement of data gathering, guaranteed freedom to agree or disagree to participate in the study, and assured that their refusal would not in any way affect them. The objectives of the study and the role of the participants were communicated in advance, and their consent was taken in writing. Data were collected on June 2010. The questionnaire was coded and entered into the SPSS program for analysis.

\section{Findings}

The main question for this study was: What are the underlying (psychological, personal, school-culture-related, organizational) factors for teacher resistance to educational change currently underway in Al-Ain government schools in the UAE? For each of the four factors, the means, standard deviations, and percentages of agreement were calculated. Table 1 presents results of the seven statements in the category of the psychological factor.

Table 1

Means, standard deviations, and percentages of agreement of the psychological factor

\begin{tabular}{|c|c|c|c|c|c|}
\hline & Items & $n$ & Mean & $S D$ & $\begin{array}{l}\text { Percentage of } \\
\text { agreement }\end{array}$ \\
\hline 1 & $\begin{array}{l}\text { I like to see educational change } \\
\text { happening in my school }\end{array}$ & 254 & 4.02 & 0.951 & 79.2 \\
\hline 2 & $\begin{array}{l}\text { I have high motivation to participate in } \\
\text { the educational change }\end{array}$ & 254 & 4.06 & 0.878 & 80.8 \\
\hline 3 & $\begin{array}{l}\text { I have fear of the unknown } \\
\text { consequences of the change }\end{array}$ & 251 & 3.56 & 1.274 & 59.3 \\
\hline 4 & $\begin{array}{l}\text { I have fear of losing my job because of } \\
\text { the change }\end{array}$ & 252 & 3.09 & 1.403 & 43.2 \\
\hline 5 & $\begin{array}{l}\text { I fear having more demand and job } \\
\text { requirements to implement the change }\end{array}$ & 252 & 3.23 & 1.344 & 49.4 \\
\hline 6 & $\begin{array}{l}\text { I feel overwhelmed by the information } \\
\text { overload }\end{array}$ & 251 & 3.19 & 1.321 & 46.7 \\
\hline 7 & $\begin{array}{l}\text { I doubt my abilities to learn something } \\
\text { new }\end{array}$ & 253 & 2.20 & 1.195 & 17.7 \\
\hline
\end{tabular}


As shown in Table 1, teachers rated the statement "I have high motivation to participate in the educational change" as the highest component in the psychological factor with a mean score of $4.06(80.8 \%)$. The teachers rated the statement "I like to see educational change happening in my school" and "I have fear of the unknown consequences of the change" as the second and third strongest psychological factors with mean scores of 4.02 (79.2\%) and $3.56(59.3 \%)$ respectively. The statement "I doubt my abilities to learn something new" was rated as the weakest factor with a mean score of $2.20(17.7 \%)$. Table 2 presents the results of the seven statements comprising the personal factor.

Table 2

Means, standard deviations and percentages of agreement of the personal factor

\begin{tabular}{|c|c|c|c|c|c|}
\hline & Items & $n$ & Mean & $S D$ & $\begin{array}{c}\text { Percentage of } \\
\text { agreement }\end{array}$ \\
\hline 1 & I see the need for educational change & 252 & 3.70 & 1.086 & 69.8 \\
\hline 2 & $\begin{array}{l}\text { I believe in the management ability to } \\
\text { implement change successfully }\end{array}$ & 254 & 4.01 & 0.956 & 79.3 \\
\hline 3 & I trust the change agents & 255 & 3.65 & 0.993 & 62.3 \\
\hline 4 & $\begin{array}{l}\text { I am aware of my role in the change } \\
\text { process }\end{array}$ & 249 & 3.54 & 1.100 & 59.3 \\
\hline 5 & $\begin{array}{l}\text { I think the change disrupts my stable } \\
\text { work norms and relations }\end{array}$ & 253 & 2.83 & 1.213 & 32.4 \\
\hline 6 & $\begin{array}{l}\text { I reject the change due to the lack of } \\
\text { conformity to norms and values }\end{array}$ & 255 & 2.62 & 1.170 & 22.7 \\
\hline 7 & I resist change because everybody does & 251 & 2.22 & 1.192 & 15.7 \\
\hline
\end{tabular}

As shown in Table 2, teachers rated the statement "I believe in the management ability to implement change successfully" as the highest component of the personal factor with a mean score of 4.01 (79.3\%). The teachers also rated the statement "I see the need for educational change" and "I trust the change agents" as the second and third strongest components with mean scores of $3.70(69.8 \%)$ and $3.65(62.3 \%)$ respectively. The statement "I am aware of my role in the change process" has a mean of 3.54 (59.3\%) and standard deviation of 1.1 -indicating not very high agreement. The statement "I resist change because everybody does" was rated as the least strong component with a mean score of 2.22 (15.7\%). Table 3 presents the results of the nine statements in the category of the school-culture-related factor.

Table 3

Means, standard deviations, and percentages of agreement of the school-culture-related factor

\begin{tabular}{|c|c|c|c|c|c|}
\hline & Items & $n$ & Mean & $S D$ & $\begin{array}{l}\text { Percentage } \\
\text { of agreement }\end{array}$ \\
\hline 1 & $\begin{array}{l}\text { The principal has to communicate proposed changes } \\
\text { to teachers }\end{array}$ & 251 & 4.08 & 0.939 & 83.9 \\
\hline 2 & $\begin{array}{l}\text { The principal has to collaborate with teachers in } \\
\text { formulating the new vision }\end{array}$ & 252 & 4.02 & 0.938 & 79.2 \\
\hline 3 & $\begin{array}{l}\text { The changes are in agreement with the school's } \\
\text { norms and values }\end{array}$ & 250 & 3.85 & 0.875 & 70.6 \\
\hline 4 & Teachers participate in planning for the change & 251 & 3.65 & 1.128 & 65.5 \\
\hline 5 & $\begin{array}{l}\text { The principal demonstrates understanding of the } \\
\text { change process }\end{array}$ & 247 & 3.96 & 1.033 & 76.9 \\
\hline 6 & $\begin{array}{l}\text { The principal has to provide guidance and support } \\
\text { during the implementation stage }\end{array}$ & 251 & 4.05 & 0.889 & 76.4 \\
\hline 7 & $\begin{array}{l}\text { The principal has to encourage collaboration among } \\
\text { staff members }\end{array}$ & 251 & 4.22 & 0.840 & 85.1 \\
\hline 8 & $\begin{array}{l}\text { Sufficient time is provided for the implementation of } \\
\text { change }\end{array}$ & 249 & 3.47 & 1.242 & 54.6 \\
\hline 9 & $\begin{array}{l}\text { The school culture encourages experimentation and } \\
\text { continuous learning }\end{array}$ & 240 & 3.93 & 1.013 & 67.5 \\
\hline
\end{tabular}


As shown in Table 3, teachers rated the statement "The principal has to encourage collaboration between staff members" as the strongest factor among the school culture factors that must be present in order for the change to succeed, with a mean score of $4.22(85.1 \%)$. This is followed by statements "The principal has to communicate to teachers the proposed changes" and "The principal has to provide guidance and support during the implementation stage" with mean scores of 4.08 (83.9\%) and 4.05 (76.4\%) respectively. Other statements such as "Sufficient time is provided for the implementation of change" and "Teachers participate in planning for the change" were rated relatively lower among the school-culture-related factor with mean scores of 3.47 (54.6\%) and $3.65(65.5 \%)$ respectively. Table 4 presents the results of the sixteen statements designated as organizational factor.

\section{Table 4}

Means, standard deviations, and percentages of agreement of the organizational factor

\begin{tabular}{|c|c|c|c|c|c|}
\hline & Items & $\mathrm{n}$ & Mean & SD & $\begin{array}{l}\text { Percentage of } \\
\text { agreement }\end{array}$ \\
\hline 1 & $\begin{array}{l}\text { The change agents assess the staff members readiness } \\
\text { for change }\end{array}$ & 247 & 3.56 & 1.126 & 62.7 \\
\hline 2 & $\begin{array}{l}\text { The change is planned and directed towards particular } \\
\text { goals }\end{array}$ & 247 & 3.90 & 1.021 & 74.2 \\
\hline 3 & The change goals are clear to all staff members & 246 & 3.34 & 1.263 & 52.9 \\
\hline 4 & The change process is comprehensible and logical & 246 & 3.46 & 1.152 & 44.5 \\
\hline 5 & The change is introduced gradually & 246 & 3.44 & 1.303 & 57.2 \\
\hline 6 & The timing of implementing the change is suitable & 245 & 3.24 & 1.240 & 47.8 \\
\hline 7 & $\begin{array}{l}\text { The successful implementation of the change is linked } \\
\text { to rewards }\end{array}$ & 245 & 3.44 & 1.305 & 52.2 \\
\hline 8 & $\begin{array}{l}\text { The teachers are trained on how to implement the } \\
\text { change }\end{array}$ & 245 & 3.57 & 1.202 & 62.0 \\
\hline 9 & The staff development activities are effective & 245 & 3.57 & 1.111 & 58.8 \\
\hline 10 & $\begin{array}{l}\text { The staff development activities meet the change } \\
\text { objectives }\end{array}$ & 241 & 3.67 & 1.158 & 65.1 \\
\hline 11 & $\begin{array}{l}\text { An effective scaffolding is required to facilitate the } \\
\text { change }\end{array}$ & 247 & 4.27 & 0.875 & 85.1 \\
\hline 12 & $\begin{array}{l}\text { The presence of coaching is essential for ensuring the } \\
\text { acquisition of skills }\end{array}$ & 245 & 4.23 & 0.970 & 83.9 \\
\hline 13 & $\begin{array}{l}\text { There is a release time for employees to cooperate to } \\
\text { solve problems }\end{array}$ & 248 & 3.42 & 1.188 & 53.7 \\
\hline 14 & There is time to implement the change & 247 & 3.29 & 1.241 & 51.8 \\
\hline 15 & $\begin{array}{l}\text { The implemented changes are evaluated for } \\
\text { effectiveness }\end{array}$ & 248 & 3.50 & 1.135 & 59.2 \\
\hline 16 & The school has a history of excessive change & 248 & 3.67 & 1.012 & 63.9 \\
\hline
\end{tabular}

As shown in Table 4, teachers rated the statements "An effective scaffolding is required to facilitate the change" and "The presence of coaching is essential for ensuring the acquisition of skills" as the two highest organizational components that must accompany in the change to succeed with mean scores of $4.27(85.1 \%)$ and $4.23(83.9 \%)$ respectively. The percentages of eight statements were in the 40s and 50s. Means of these statements are below 4 and standard deviations are above 1 suggesting that these organizational factors lead to teachers' resistance. The most important of these statements are "The change process is comprehensible and logical", "The change goals are clear to all staff members", "The successful implementation of the change is linked to rewards", "The change is introduced gradually", and "The staff development activities are effective". 
The survey included an open-ended question following each of the four factors to inquire about three missing areas in each factor, if any. With regard to the psychological factor, teachers "[felt] overwhelmed with the added responsibilities that most of the time was not relevant to teaching". In addition, they were worried about "extending the school working hours". They needed to be prepared psychologically for change since their psychological stability was important for change to happen. Talking about the personal factor, teachers indicated facing hard times implementing the new curriculum since "many students are not prepared for using the English language". They added that the curriculum has to be up to the level of students and "conforms to the UAE norms".

With regard to the school-culture-related factor, teachers indicated that "the change was imposed on them" and "they were excluded from planning for the change". They see a need for change to fit the school culture. They preferred principals who encourage collaboration as "cooperation among teachers is not high in schools". Some also argued that "change should not rely on the foreigners due to the fact that they would jeopardize the religion and culture of the UAE".

Teachers suggested that "change has to be done on small scale and when it proves to be successful, it would be generalized". It also has to be done gradually with "realistic and achievable goals". They argued that coordination among the school administration, the school district and ADEC is not high and therefore "there is a feeling of different sources of change". As a consequence, they sometimes feel they are lost in the change process.

\section{Discussion}

In reference to the psychological factor, Margolis and Nagal (2006) asserted that the cumulative stress from physical and mental exhaustion negatively affects the job performance and satisfaction of teachers. Moreover, Palmer et al. (2009) indicated that discomfort of the uncertainty is one of the causes of resistance of teachers. The findings in our current study are in line with those results: teachers want to have educational change and they are willing to participate in the change; however, the way changes are introduced can also create feelings of fear. It seems that the change was introduced without involving them in the planning process; they were not prepared for the change a head of time; and the change was felt to be imposed on them rather than emanating from the realities of their work. Moreover, teachers were not happy with the added responsibilities and the extended working hours. The new curriculum required them to teach in English—a language which needed much effort and time from them to improve (see also Mckenzie \& Scheurich, 2008).

With regard to the personal factor, Graetz, Rimmer, Lawrence, and Smith (2002) found that teachers resist change when they consider it to be unnecessary. This study showed that teachers consider change as necessary. However, they still resist not because of the necessity/unnecessity of change but because of other factors. Hinde (2002) indicated that the teachers' values and norms influence their views of education and change. In other words, change that is different from school culture and norms will be resisted (as cited in Hinde, 2004). The findings of this study support the same idea. In fact, teachers showed high resistance to change that is not aligned with the school culture or that of the Emirati society in general. In the open-ended sections of the survey, teachers mentioned that students faced difficulty in understanding the new curriculum that was introduced in English. This might be due to language barriers. Teachers felt that it is unfair for them and for students to start this new curriculum, especially with students who were used to the old curriculum.

Focusing on the school-culture-related factor, Palmer et al. (2009) pointed out that managing change can be facilitated by having a principal who is visionary and who uses effective communication strategies to reinforce change. Further, McGregor (2002) asserted the importance of a visible principal who advocates for change. The principals have the responsibility of becoming change agents. Their role in creating and sustaining a culture of learning in their schools and increasing the willingness of teachers to accept change is un-debatable. It seems that most of Al-Ain government school principals lack the ability to create such a culture. This is manifested in 
teachers' attitudes toward change. The schools with traditional administration styles, which neither allow teachers to formulate the school vision nor participate in making decisions result in resistance to change that originates from lack of awareness of change or misunderstanding its process. The presence of newly-hired, foreign teachers in schools increased the level of resistance. Emirati teachers are afraid that foreign teachers will transmit cultural and behavioural patterns that contradict the conservative culture of students.

Referring to the organizational factor, Waddell, Cummings, and Worley (2000) found that one reason which slows down the progress of change is deficiency in planning. Lack of guidance and support during the implementation of change, the deficiency in providing training on how to put change into action, and lack of a reward system for those who successfully adopt the change would all lead to resistance. According to the teachers' views in this study, it seems that all of those points are evident in the current change. Adding to this is the existence of different plans and different initiators of change. In other words, current change comes in different shapes and from different sources. Teachers did not know exactly what to do and which plan they should follow. They were not able to effectively implement the educational change because things were unclear and unstructured. This created a feeling of insecurity. What they needed, they argued, is a well-planned, coordinated, and clear change that suits their abilities, those of students, and the Emirati culture.

\section{Conclusions}

Research confirms that resistance is expected with any change. This study concluded that resistance to educational change proposed by ADEC would increase if the change is not planned well, teachers are not involved in the planning process, teachers are not provided with effective training on implementing change, a culture for learning and a willingness to change do not prevail, or a rewarding system does not exist. In addition, the absence of direction for change (or as referred to by participants in this study 'the mismatch between the different plans and initiators of change') would lead to resistance as teachers will not be able to see their way. Moreover, frequent changes that took place simultaneously hindered the acceptance of change and created the feeling of insecurity and fear. The most distinctive factor for resistance that was evident in the UAE context is that teachers were worried about their cultural values and norms, which might be jeopardized by the new curriculum created mostly by foreign consultants. This view reflects the conservative nature of teachers in UAE schools and how much they care about protecting their culture.

\subsection{Recommendations}

The study recommends that ADEC officials, the school superintendent, and school principals spend more effort to alleviate teachers' fears of the unknown consequences of the change undertaken in Al-Ain government schools (and in other regions of the emirate). The rationale behind change should be explained; teachers should be included in the planning process and provided with effective professional development during the change process. Moreover, policy makers should consider reviewing the curriculum to align it more with students' needs, academic levels, and the UAE culture. Researchers are encouraged to replicate the study in other school districts in the country, preferably using a larger sample. Administrative staff could be included in further research to investigate their perceptions of change. A longitudinal study should be carried out to assess ADEC's change and the extent to which teachers' resistance has been increased or decreased over time. Moreover, a qualitative research design with observations and interviews can be utilized to deeply explore the difficulties of implementing change.

\section{References:}

ADEC. (2010). Education Statistics First: 2010 Statistical Factbook Emirate of Abu Dhabi, Primary and Secondary Education. Abu Dhabi: ADEC.

Al Ateeqi, A. (2009). We have come along way: Redefining education and its global challenges in the United Arab Emirates. Paper presented at the 2009 Education without Borders Conference, March 2009, 
Dubai.

Beckum, I. (2010). A case study of teachers' perceptions of change and change implementation at a rural public school. Doctoral dissertation. Walden University, Minnesota.

Calabrese, R. (2006). Trapped by central administration's focus on NCLB: Teacher's struggling with professional development in an urban middle school. Journal of Research for Educational Leaders, 3(2), 39-59.

DuFour, R., DuFour, R., \& Eaker, R. (2008). Revisiting professional learning communities that work: New insights for improving schools. Bloomington, IN: Solution Tree.

Flamholtz, E., \& Randle, Y. (2008). Leading strategic change: Bridging theory and practice. New York: Cambridge University Press. http://dx.doi.org/10.1017/CBO9780511488528

Fullan, M., \& Ballew, A. (2004). Leading in a culture of change: Personal action guide and workbook. San Francisco: Jossey-Bass.

Gaylor, T. (2001). Factors affecting resistance to change: A case study of two North Texas Police department. Master's thesis. University of North Texas.

Graetz, F., Rimmer, M., Lawrence, A., \& Smith, A. (2002). Managing organizational change. Milton, Queensland, Australia: John Wiley and Sons Ltd.

Gray, C. (2002). Entrepreneurship, resistance to change and growth in small firms. Journal of Small Business and Enterprise Development, 9(1), 61-72. http://dx.doi.org/10.1108/14626000210419491

Hind, E. (2004). School culture and change: An examination of the effects of school culture on the process of change. Retrieved from http://www.usca.edu/essays/vol122004/hinde.pdf

Kezar, A., \& Eckel, P. (2002). The effect of institutional culture on change strategies in higher education. The Journal of Higher Education, 73(4), 435-460. http://dx.doi.org/10.1353/jhe.2002.0038

Kise, J. (2005). Coaching teachers for change: Using the concepts of psychological type to reframe teacher resistance. Journal of Psychological Type, 65(6), 48-58.

Margolis, J., \& Nagal, L. (2006). Education reform and the role of the administrators in mediating teacher stress. Teacher Education Quarterly, 33(4), 143-159.

McGregor, J. (2002). Flexible scheduling: How does a principal facilitate implementation? School Libraries Worldwide, 8(1), 71-84.

Mckenzie, K., \& Scheurich, J. (2008). Teachers resistance to improvement of schools with diverse students. International Journal of Leadership in Education, 11(2), 117-113. http://dx.doi.org/10.1080/13603120801950122

Palmer, I., Dunford, R., \& Akin, G. (2009). Managing organizational change: A multiple perspectives approach. New York: McGraw-Hill Education.

Per, D. (2004). School development: Theories and strategies. Portland: Continuum International Publishing Group.

Rayan, S., \& Ackerman, D. (2005). Using pressure and support to create a qualified workforce. Education Policy Analysis Archives, 13(23), 1-19.

Silcox, S., MacNeill, N., \& Cavanagh, R. (2003). Principal leadership and school renewal. Paper presented at the 2003 Annual Conference for the Australian Association for Research in Education. Auckland. Retrieved from http://aare.edu.au/03pap/sil03419.pdf

Silcox, S., MacNeill, N., \& Cavanagh, R. (2004). Conceptualizing principal leadership of school renewal. Paper presented at the 2004 Annual Conference for the Australian Association for Research in Education. Melbourne. Retrieved from www.aare.edu.au/04pap/sil04441.pdf

Troudi, T., \& Alwan, F. (2010). Teachers' feelings during curriculum change in the United Arab Emirates: Opening Pandora's box. Teacher Development: An International Journal of Teachers' Professional Development, 14(1), 107-121.

Van Veen, K., \& Sleegers, P. (2006). How does it feel? Teachers' emotions in a context of change. Journal of Curriculum Studies, 38(1), 85-111. http://dx.doi.org/10.1080/00220270500109304

Waddell, D., Cummings T., \& Worley, C. (2000). Employee involvement: Organizational development and change. Australia: Nelson Thomson Learning. 
Ibrahim, A. S., Al-Kaabi, A., \& El-Zaatari, W. 